\title{
Effect of Dissemination of Resources and Information Method for Overnutrition Prevention Behavior on Primary School Children in Makassar
}

\author{
Anto J. Hadi ${ }^{1,2}$, Jusman Usman ${ }^{1}$, Syamsopyan Ishak ${ }^{2}$, Erni Yetti $\mathbf{R}^{3}$, \\ Saskiyanto Manggabarani ${ }^{4}$, Muhammad Anwar ${ }^{5}$, Ahmad Safii Hasibuan ${ }^{2}$ \\ ${ }^{1}$ Public Health Department, Faculty of Public Health, Universitas Indonesia Timur, Makassar, ${ }^{2}$ Public Health \\ Department, Faculty of Health, Universitas Aufa Royhan, Padangsidimpuan, Indonesia, ${ }^{3}$ Health Promotion \\ Departement, Midwifery Academy of Sinar kasih Toraja, Tana Toraja, Indonesia, ${ }^{4}$ Nutrition of Program Study, \\ Sekolah Tinggi Ilmu Kesehatan Pertamedika, Jakarta, Indonesia, ${ }^{5}$ Health Promotion Departement, Faculty of \\ Public Health, Universitas Al Asyariah, Polewali, Indonesia
}

\begin{abstract}
The prevalence of overnutrition among primary school aged children, which ranges from the risk of obesity globally including Indonesia, is currently increasing. This study aimed to assess the difference in behavior change in physical activity and habit of soft drinks consumptions before and after the intervention with the dissemination method of resources and information. The research was conducted at primary schools in Makassar City. This research used a Quasy Experiment approach with a pretest and post-test examination through control group design. The study was conducted for 3 months by providing health information related to overnutrition and obesity while monthlyvisit or monitoring of children was carried out using a 24 hour food recall. The sampling technique was carried out by means of proportional random sampling. Data were analyzed by univariate, bivariate, and multivariate analysis. The results showed that there was an effect of dissemination of resources and information on physical activity $(p=0.000)$ and soft drink consumption habits $(p=0.000)$ before and after the intervention. The conclusion is that the application of the method of dissemination of resources and information is effective in changing the behavior of preventing overnutrition in primary school children. It is expected that efforts in schools such as the method of dissemination of resources and information with peer education will become a reference in efforts to prevent more nutrition in improving students' healthy eating patterns through dissemination of resources and information.
\end{abstract}

Keywords: Physical Activity; Soft Drink Consumption; Overnutrition.

\section{Introduction}

The prevalence of overnutrition among primary school aged children in the world has increased over the last few decades due to changes in shifting eating habits

\section{Corresponding Author:}

\section{Anto J. Hadi}

Public Health Department, Faculty of Health, Universitas Aufa Royhan, Kota Padangsidimpuan, North Sumatera Province, Indonesia

Phone: 085242877376

e-mail: antoarunraja@gmail.com such as soft drinks consumption and low physical activity with the following risks ${ }^{(1)}$. Globally, the prevalence of overweight and obesity in children of 5-17-old years is $10 \%^{(2)}$. Based on Riskesdas (2018), it shows that the prevalence of overweight in South Sulawesi province is $13.6 \%$ obese and $21.8 \%$ obese. Meanwhile, in Makassar City children are $13.9 \%$ overweight and $16.5 \%$ obese $^{(3)}$. School age children who are overweight and obese are included in the vulnerable group ${ }^{(4)}$.

The consequences of obesity for schoolaged children will have an impact on social stigma. They are being bullied by their playmates, have experienced discrimination, and appear to have low self-esteem. Preventing overnutrition is prioritized in primary 
prevention efforts, namely promotion efforts, which means it is started from the school and home environment. Preventive action is the best and safest way for school aged children who are still in their infancy. The basic principle of preventing over nutrition in primary school children is to increase physical activity, increase movement and limit the consumption of foods that contain calories ${ }^{(5)}$. The nutrition education method used in primary school children can involve students so that students feel responsible for determining the healthy behavior they should do and are given nutritional information. In addition, many studies that analyze the factors affecting that cause obesity and determine obesity prevention method in primary school age children have not been widely carried out recently. This is the gap research and can be done by the method of dissemination of resources and information. This method is carried out in the form of providing nutritional information ${ }^{(6)}$. Therefore, there is still a need for a method of obesity prevention based on peer nutrition education in an effort to reduce the prevalence of obesity and improve childrens' health status by means of dissemination of resources and information. This study aimed to assess the differences in changes in physical activity and consumption habits before and after the intervention using the dissemination of resources and information method. Further study on the factors affecting is needed to conduct so that we can prevent the cases of obesity and overweight primary school aged children.

\section{Method}

This research uses a "Quasy Experiment" design, namely pretest and post-test with a control group design.
The research was conducted at primary schools in Makassar City. The research intervention was conducted withthree months period by providing dissemination of resources and information related to obesity and overnutrition cases in children. Monthly student visit or monitoring was conducted regularly. The research instrument were a form of recall food, digital scales, and microtise, determining the student BMI using the WHO Antrhoplus software. The sampling technique was carried out by means of Sample Size Determination in Health Studies and proportional random sampling ${ }^{(7)}$. Data were analyzed using the chi-square test, Independent T-Test, Mann Whitney, Wilcoxon test, and hotelling test. The results then reflected to the case of obesity in primary school aged children.

\section{Results}

The distribution of student characteristics can be seen in Table 1, which shows the largest proportion of the age group before the intervention, namely 9 years of age in the intervention group (52.5\%), the majority of whom were female $(52.5 \%)$, and were in class IV $(70.0 \%)$. While in the control group, the oldest children was aged 9 years $(45 \%)$, the majority were male $(60.0 \%)$, and were in class IV and V (50\% and 50\% respectively from both classes). The results showed that there was no difference in the proportion of age, sex, and class before the intervention $(p>0.05)$. Based on the average BMI/age before the intervention, the highest in the intervention group was $20.60 \pm 2.21$, while there was a difference in the average before nutrition education was given in the treatment group and the control group $(\mathrm{p}<0.05)$.

Table 1. Students Characteristics Distribution on Each Group of Primary School Children in Makassar City

\begin{tabular}{|l|c|c|c|}
\hline \multirow{2}{*}{ Variable } & Intervention $(\mathbf{n}=\mathbf{4 0})$ & Control $(\mathbf{n}=\mathbf{4 0})$ & \multirow{2}{*}{$\mathbf{p}$} \\
\cline { 2 - 3 } & Mean \pm SD/\% & Rerata \pm SD/\% & \multirow{2}{*}{$0.160^{*}$} \\
\hline Age Group (1-year-old) & $22(53.5)$ & $19(46.0)$ & \\
9 & $13(34.0)$ & $9(24.0)$ & \multirow{2}{*}{$0.262^{*}$} \\
10 & $5(13.4)$ & $12(30.0)$ & \\
\hline Gender & $19(47.5)$ & $24(60.0)$ & $0.068^{*}$ \\
Male & $21(52.5)$ & $16(40.0)$ & \\
Female & $28(70.0)$ & $20(50.0)$ & $0.030^{* * *}$ \\
\hline Class & $12(30.0)$ & $20(50.0)$ & $19.14 \pm 4.15$ \\
IV & $20.60 \pm 2.21$ & & \\
V & & & \\
\hline BMI/A & & & \\
\hline
\end{tabular}

*Chi Square; **Independen T-Test; ***Mann Whitney 
Table 2. Changes in Students' Physical Activities Before and After Intervention

\begin{tabular}{|l|c|c|c|c|c|c|c|}
\hline Aktivitas Fisik & Pre & Post 1 & $\mathbf{p}^{*}$ & $\mathbf{\Delta 1}$ & Post 2 & $\mathbf{p}^{*}$ & \multicolumn{1}{|c|}{$\mathbf{2}$} \\
\hline Intervention & $22.93 \pm 1.40$ & $34.05 \pm 1.53$ & $(0.000)$ & $\uparrow 10.13 \pm 1.84$ & $43.78 \pm 1.18$ & $(0.000)$ & $\uparrow 19.85 \pm 1.62$ \\
\hline Control & $13.35 \pm 1.76$ & $19.33 \pm 1.18$ & $(0.000)$ & $\uparrow 5.98 \pm 1.77$ & $24.40 \pm 0.87$ & $(0.000)$ & $\uparrow 11.05 \pm 1.63$ \\
\hline $\mathrm{p}^{* *}$ & & & & 0.000 & & & 0.000 \\
\hline
\end{tabular}

$\Delta 1=$ Difference of Pre-Post $1 ; \Delta 2=$ Difference of Pre-Post $2 ; *$ Wilcoxon Test; **Mann Whitney Test

The highest average score of physical activity in Table 2 in the pre group is in the intervention group, which is 22.93. Likewise at post-test 1 , the highest average value was found in the intervention group, which is 34.05 . Based on the Wilcoxon test results, it showed that both the intervention and control groups had a significant difference between pretest and post-test $1(\mathrm{p}$ $<0.05$ ) of the physical activity scores. In addition, there was an increase in physical activity scores from pretest to post-test 1 for each group, where the highest increase was in the intervention group, which is 10.13 . Based on the Mann Whitney test, there was a significant difference $(p<0.05)$ from the difference in score improvement for the two groups. Meanwhile, the average score of physical activity at post-test 2 was the highest in the intervention group, namely 43.78. Based on the Mann Whitney test, there was a significant difference $(p<0.05)$ from the difference in score improvement for the two groups.

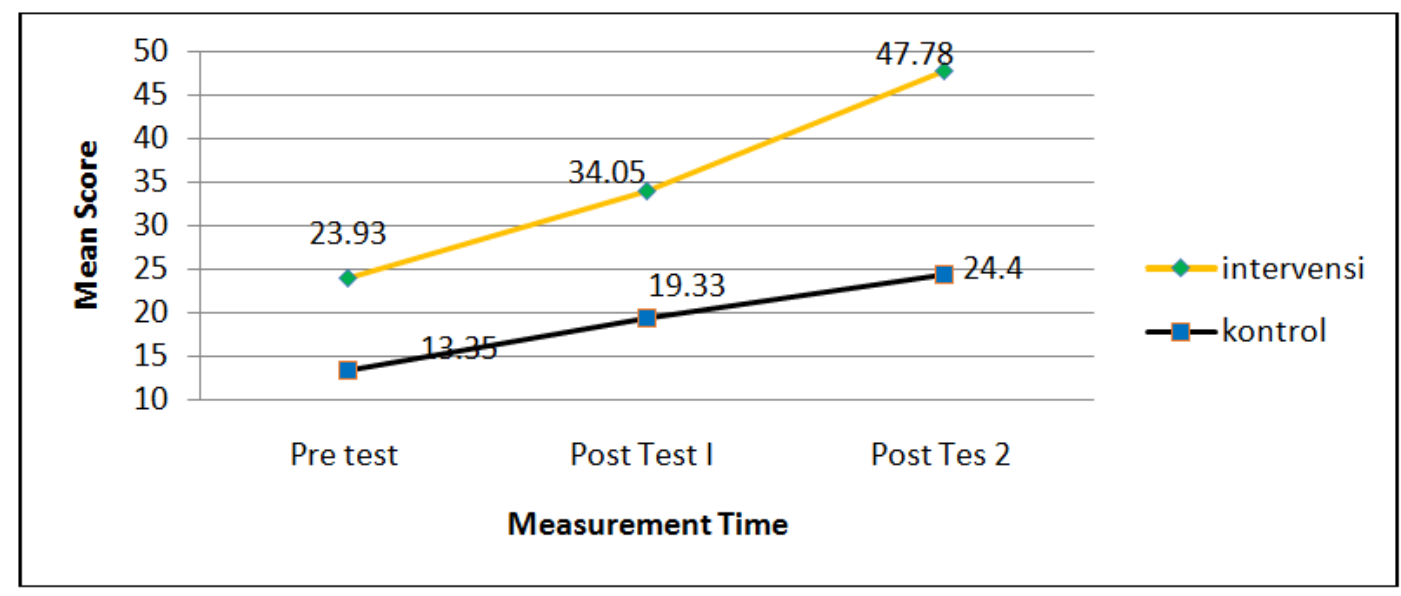

Figure 1. Changes in Students' Physical Activities

It can be seen that the average score of high students' physical activity in the intervention group compared to the control group from baseline has increased, from the beginning of the experiment, the progress happened in post-test 1 , and the progress happened in post-test 2 .

Table 3. Changes in Students' Soft Drink Consumption Before and After Intervention

\begin{tabular}{|l|c|c|c|c|c|c|c|}
\hline $\begin{array}{l}\text { Soft Drink } \\
\text { Consumption }\end{array}$ & Pre & Post 1 & $\mathbf{p}^{*}$ & $\boldsymbol{\Delta 1}$ & Post 2 & $\mathbf{p}^{*}$ & $\boldsymbol{\Delta 2}$ \\
\hline Intervention & $70.95 \pm 1.66$ & $58.75 \pm 1.99$ & $(0.000)$ & $\downarrow 12.20 \pm 1.47$ & $45.83 \pm 2.76$ & $(0.000)$ & $\downarrow 25.13 \pm 2.46$ \\
\hline Control & $71.78 \pm 0.57$ & $68.85 \pm 0.66$ & $(0.000)$ & $\downarrow 2.93 \pm 0.76$ & $61.83 \pm 0.67$ & $(0.000)$ & $\downarrow 9.95 \pm 0.81$ \\
\hline $\mathrm{p}^{* *}$ & & & & 0.000 & & & 0.000 \\
\hline
\end{tabular}

$\Delta 1=$ Difference of Pre-Post $1 ; \Delta 2=$ Difference of Pre-Post $2 ;{ }^{*}$ Wilcoxon Test; **Mann Whitney Test 
Table 3 shows the highest average score of soft drink consumption habits in the pretest is in the control group, which is 71.78 . While at post-test 1 , the lowest average value was in the intervention group, which is 58.75. Based on the Wilcoxon test results, it showed that both the intervention and control groups had a significant difference between the scores for the habit of soft drink consumption at pretest and post-test 1 ( $p$ $<0.05$ ). In addition, there was a decrease in the score of soft drink consumption habits from pretest to post-test 1 for each group (intervention and control group), where the highest decrease was in the intervention group, which is 12.20. Based on the Mann Whitney test, there was a significant difference $(p<0.05)$ from the difference in score reduction for the two groups. While the average score for the habit of soft drink consumption at posttest 2 was the lowest in the intervention group, which is 45.83. Based on the results of the Wilcoxon test, there was a significant difference between the scores for the habit of soft drink consumption at pretest and post-test $2(\mathrm{p}<0.05)$.

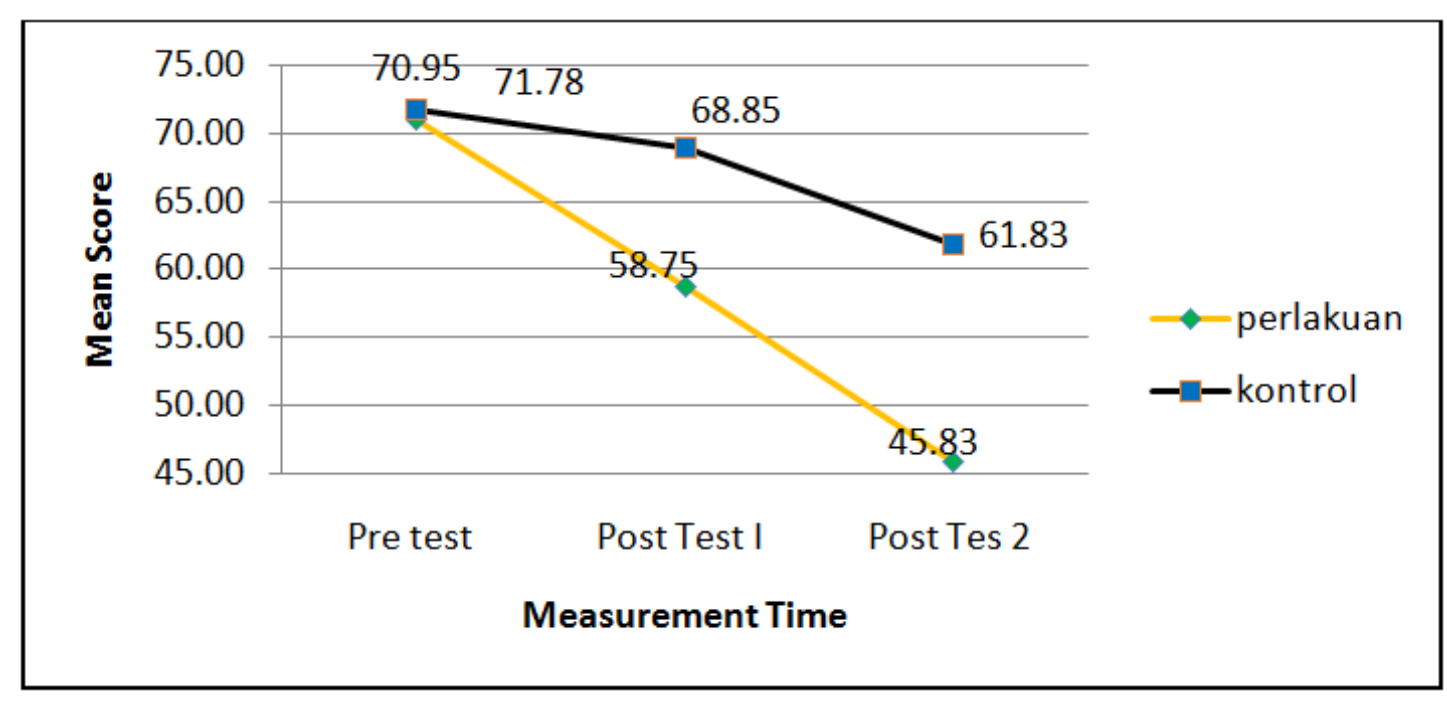

Figure 2. Changes in Students' Soft Drink Consumption

Figure 2 shows that the average score of students' soft drink consumption habits was higher in the control group than the average score of students' soft drink consumption habits at the intervention group at the beginning of the measurement. Between post-test 1 and post-test 2, the average score of students' soft drink consumption habits was lower in the intervention group than in the control group. Multivariate analysis was used to simultaneously assess both groups before and after intervention/treatment applied to the intervention group.

Table 4. Multivariate Results of Changes in Students' Physical Activities and Students' Soft Drink Consumption Habits

\begin{tabular}{|c|c|c|c|}
\hline Nutrition Peer Educator & Value & $\mathbf{F}$ & $\mathbf{p}$ \\
\hline Hotelling's Trace & 643.42 & 3716.72 & 0.000 \\
\hline Students' Physical Activities & 7507.81 & 6924.14 & 0.000 \\
\hline Students' Soft Drink Consumption Habits & 5120.00 & 1265.60 & 0.000 \\
\hline
\end{tabular}

Table 4 shows that the results of statistical tests with Hotelling's $\mathrm{T}$ test obtained the value of $\mathrm{F}=$ 3716.72 and $p=0.000(p<0.05)$. This means that there are differences in the students' physical activities who receive the treatment of dissemination of resources and information with students' physical activities who did not receive the treatment of dissemination of resources and information. Based on the results of the analysis, it was found that the students' physical activity variable was the most influential among the other variables due to 
the reinforcing factor of the treatment of dissemination of resources and information so that there was an increase in understanding of students' physical activity after the intervention and greatly influenced the formation of preventive behavior patterns for students resulting in changes in decreasing the incidence of overnutrition cases in primary school aged children.

\section{Discussion}

\section{Health and Nutrition Education through Dissemination of Resources and Information Method} on Students' Physical Activities: Physical activity is one of over nutrition prevention forms. Physical activity can burn calories in students while the use of technology can positively prevent obesity. If we combine both ways to prevent obesity in children, the case of diseases caused by obesity will decrease. Children physical activity is needed in the form of running, playing basketball, playing soccer, and playing futsal. Beside decreasing obesitycases, physical activities can improve daily childrens' health. Therefore, the role of teachers, health workers, and parents of students ${ }^{(8)}$ is very important to provide information related to the importance of moving and doing physical activity, can prevent overweight in students, and can monitor students' physical activity continuously by applying the rules of a healthy lifestyle in the environment,at school, and at home. Based on the Wilcoxon test, the $\mathrm{p}$ value was obtained $<0.05$, which means that there was a difference in physical activity between the treatment group and the control group at post 1 and post 2 . Based on the results of the analysis there were differences in the physical activity of students after the treatment in the intervention and control groups, changes in physical activity indicated that there was increase to $100 \%$ in the third month while the physical activity of the control group students decreased. This proves that there is an effect of the dissemination of resources and information method intervention on students' physical activities.

The physical activity of obese children increases and can reduce and reduce the consumption of food and drinks that have an impact on weight loss. Strenuous physical activity and more sweating is very effective in losing more weight than by adjusting only a diet ${ }^{(9)}$. Therefore, doing physical activity can maintain human body functions to be more optimal, so that it can reduce the risk of obesity. Proper and optimum metabolism can help enhancing good body shape. The high student consumption of calorie intake that exceeds the need has a negative impact on increasing body weight over normal body weight. It is influenced by increased family income and the ease of buying food and drinks so that more nutritional sufferers increase and become a risk factor for obesity ${ }^{(10)}$. The incidence of overweight in primary school students in Makassar City tends to be light activities compared to heavy student activities. This is in line with Erni Yetti (2018) research showing that fat intake is higher in students with less activity levels so that students who are less active in movement have the opportunity to experience more nutrition or fat ${ }^{(11)}$. In this study, activities that are usually carried out in the home environment are cycling and playing football, while at home children sometimes play video games, computers, and watch television. In physical activity, it can be seen that there is a decrease in physical activity in the third month of the intervention due to the influence of the rainy season, so that children's activities are being at home by playing video games or watching television which can also affect changes in students' body mass index. It can lead to fluctuated body mass index in students and students' health.

\section{Health and Nutrition Education through} Dissemination of Resources and Information Method on Students' Soft Drink Consumption Habits: Soft drinks are carbonated drinks added with flavorings and sweeteners such as additive ingredients and sugar ${ }^{(12)}$. Soft drink consumption habits put a negative impact on health to both short term and long-term period. Unfortunately, students tend to consume these kinds of drink. The results showed that all students owned soft drinks consumption habits obtained from the posttest 1 and post-test 2 which decreased when the scores were compared to the pretest. It shows that there are differences in the soft drink consumption habits between the pretest and post-test 1 and post-test 2 in both the intervention and control groups. This is influenced by the method of dissemination of resources and information. The decline in soft drink consumption habits was higher in the intervention group than in the control group. The results of the Wilcoxon test obtained that a $\mathrm{p}$ value $<0.05$, which means that there is a difference in soft drink consumption habits between the intervention group and the control group at post-test 1 and posttest 2. One of several factors cause an increase in the prevalence of overnutrition globally in students is soft drink consumption habits. This finding was obtained because the students' soft drink consumption habits were influenced by the factor of knowledge, where the 
knowledge of lack of nutrition was caused by rarely getting information or nutrition counseling related to the adverse effects of consuming soft drinks. In addition, consuming soft drinks can increase body weight so that students can become overweight if they have consumed soft drinks continuously. The high glucose content can lead to overnutrition and more importantly can lead to obesity cases among children. A study by Collins et al. (2015) concluded that students who have a hereditary history of obesity have the opportunity to be overweight due to the habit of consumption high-sugar fast food. The increased risk of overnutrition can be prevented and limited by consuming low sugar levels of foods and drinks. It can also be maintained by actively engaged in regular physical activities such as running, cycling, and playing basketball. Students also need to getting used to consuming fruits and vegetables ${ }^{(13)}$. Prevention of overnutrition at school and family environment can be done by implementing a healthy diet according to a balanced menu, monitoring children's foods and drinks, limiting pocket money, scheduling reports on children's foods and drinks consumed for one day, and measuring the children's weight regularly to map the difference between before and after the measurement at least once a week. Children's physical activities can also be increased actively.

\section{Conclusions}

The conclusion of this study is that there is an effect of the method of dissemination of resources and information before and after the intervention on students' physical activity and students' soft drink consumption habits which have an impact on increasing student overnutrition prevention behavior and reducing the prevalence of overweight cases.

Funding Sources: The funding sources in this study were established from personal funds during the research conducted and analysis of factors affecting in students' overnutrition cases. This research was supported by the Directorate of Research and Community Service, the Directorate General of Research and Development Strengthening.

Acknowledgments: The authors wish to thank all the Public Helath students who helped in the collection of the data during the research of children overnutrition cases.We also acknowledge the Makassar City Government, the Health Office, and the Head of the Community Health Center in Makassar which had given the research permission. We also like to thank all of respondent who have been willing to give their consents and time during the interview process.

Internal Conflict: The author(s) declare that they have no conflict of interest during the research conducted and analysis of factors affecting in students' overnutrition cases in Makassar City.

Ethical Clearance: Ethical approval of this study has been obtained from Ethical Commission of Health Research, Faculty of Public Health, with the protocol number of UH910183005.

\section{References}

1. Hadi AJ, Hadju V, Indriasari R, Sudargo $T$, Nyorong M. Model of Peer intervention Assessment of Nutritional Educator in the Efforts to Change Behaviour in Decreasing Overweight in integrated islamic Elementary Schools at Makassar. Indian J Public Heal Res Dev. 2019;10(9):613-8.

2. González GR, Villanueva JS, Alcantar VER, Quintero AGG. Overweight and obesity in children and adolescents in full time schools Morelos, Mexico. Nutr Hosp. 2015;32(6):2588-93.

3. Indonesia KKR. Hasil utama Riskesdas 2018. Jakarta Badan Penelit dan Pengemb Kesehatan, Kementrian Kesehat Republik Indones. 2018;

4. Flego A, Dowsey MM, Choong PFM, Moodie M. Addressing obesity in the management of knee and hip osteoarthritis-weighing in from an economic perspective. BMC Musculoskelet Disord. 2016;17(1):233.

5. Organization WH. Report Obesity: Preventing and managing the global epidemic 894. Geneva. WHO Tech Rep Ser. 2000;894.

6. McDonald J, Roche AM, Durbridge M, Skinner N. Peer education: From evidence to practice (an alcohol and other drugs primer). Adelaide Natl Cent Educ Train Addict. 2003;

7. Pett MA. Nonparametric statistics for health care research: Statistics for small samples and unusual distributions. Sage Publications; 2015.

8. Anwar M, Sirajuddin S, Amiruddin R, Thaha R, Sudargo T, Hadi AJ. The Effect of Health Social Determinant on the Life Quality of Pregnant Mother. Indian J Public Heal Res Dev. 2019;10(10):16048.

9. Whitlock EP, O’Connor EA, Williams SB, Beil 
TL, Lutz KW. Effectiveness of weight management interventions in children: a targeted systematic review for the USPSTF. Pediatrics. 2010;peds2009.

10. Foster GD, Sherman S, Borradaile KE, Grundy KM, Vander Veur SS, Nachmani J, et al. A policybased school intervention to prevent overweight and obesity. Pediatrics. 2008;121(4):e794-802.

11. R EY, Safar M, Zulkifli A, Indriasari R, Tombeg Z. The Association between Eat Culture and Obesity among Adolescents in Tana Toraja. 2018;9(11).
12. Saad S, Al-Sager MO, Al-Maadeed N, AIJa'am JM. Play, Learn and Eat Healthy Food: A Mobile Game for Children to Fight Obesity. In: 2018 International Conference on Computer and Applications (ICCA). IEEE; 2018. p. 369-76.

13. Collins B, Capewell S, O'Flaherty M, Timpson H, Razzaq A, Cheater S, et al. Modelling the health impact of an english sugary drinks duty at national and local levels. PLoS One. 2015;10(6):e0130770. 